\title{
Evaluation of Libraries and Informations Units: A Proposition to Adopt Participatory Research Techniques In Order To Build Management Tools
}

\author{
Rosemeire B Tavares ${ }^{1} \&$ Custódio J Oliveira ${ }^{2}$ \\ ${ }^{1}$ Information Science School, Brasília University, Brasília, Brazil. \\ ${ }^{2}$ Business School, Brasília University, Brasília, Brazil. \\ Correspondence: Rosemeire B. Tavares, Information Science School, Brasilia University, Brasilia, Brazil - Address: \\ SQS 307, Bloco H, Apartamento 501, Post Code 70354-080; Custodio J. Oliveira, Business School, Government of \\ Brasilia, Distrito Federal, Brazil. Address: SQN 309, Bloco A, Apartamento 213, Post Code 70755-010.
}

Received: October 30, 2015

Accepted: November 17, 2015 Available online: November 23, 2015

doi:10.11114/ijsss.v4i1.1211

URL: http://dx.doi.org/10.11114/ijsss.v4i1.1211

\begin{abstract}
Introduction. We report an investigation designed to present a specific model to build management tools for libraries and information units. A management evaluation model is shown to be necessary, because these units are undergoing transformations more sharply than other organizations, therefore changes and strategies need to be monitored and controlled.

Method. Questionnaires, interviews, meetings and documentary research were conducted with a researcher at Brasíia University, Brasília, Brazil. Participative methodology was used for data collection in order to get staffs commitment and involvement in the process of building management tools. Participative research showed important because its use helped participants to solve problems as well as to deal with control and management tolls.

Analysis. Transcription of the interviews, recorded tape of meetings, documents and questionnaires tabulation formed the data for analysis. Principles of grounded theory were adopted, notably coding that allows recursive data analysis to be used to obtain the consensus from participants about what need to be measured.

Results. It proved possible to build management tools for libraries and information units applying participatory techniques. The investigation resulted in a set of coherent and fully contextualized indicators for a selected information unit.

Conclusions. Participatory techniques appear to be appropriated to enable managers and employees to handle information in order to solve problems. Commitment and involvement of participants were observed, and this is the most important finding of this investigation.
\end{abstract}

Keywords: participatory techniques, management, indicator for evaluation and control, libraries, information units

\section{Introduction}

This study presents a discussion about the efficiency, efficacy, and effectiveness of libraries and information units. The main aim is to propose a model to define management instruments in order to monitor and evaluate organizational processes. Many authors in both management and information science point to evaluation tools based on indicators. More importantly, they also point to participatory techniques cause these practices have shown the best way to achieve staff commitment and involvement.

Management instruments are necessary for two reasons. On the one hand information units have some characteristics that are similar to those of other organizations. On the other, technological and informational breakthroughs have provoked changes in the way that researchers produce knowledge and technology, and this production needs to be monitored inside libraries and/or information units.

Methodological procedures are grounded on a critical thinking perspective, within the subjetivist epistemology. Participatory research and action is the technique used for investigation, in which employees, managers and researcher work together. It is about learning organization processes that was built with an effective participation of employees and within an effective process of discussion, negotiation and consensus. 
Questionnaires, interviews, meetings and database search were the instruments used to gather data. For data analysis, the principles of grounded theory have been adopted, especially coding, in order to promote a recursive data analysis. The main aim was to achieve a measuring reference to evaluate and control management processes to be used in libraries and information units.

The application of the concepts and testing of the model were conducted in a research information Centre, located in Brasilia Federal District, Brazil. The investigation resulted in a set of fully coherent indicators in context of organization and environment.

This article is divided into five sections. The first is this introduction; the second to discuss issues from management by indicators; the third to describe the methodological procedures adopted to build the management model; the fourth presents and discusses the findings; and section fifth concludes the article.

\section{Management by Indicators}

Management by indicators, as an administrative process, focuses on the production of management information to support the decision-making process. The indicator of measurement results in strategic information of great added value.

The information management issue has been intensively discussed in the context of information science. Digital information, the Internet, free information repositories, open access to scientific and technological information, these and several other current events have caused structural changes in information units, notably libraries and research centres.

Management assumes ambiguities and uncertainties (Choo, 2006). We live in a technologically advanced environment, in which information circulates quickly and widely and where competitiveness between people (for employment), companies (for results), societies (for development and welfare), is increasingly fierce. A bad decision taken or good decision taken at the wrong time could both mean the extinction of a business and/or the delay in the development of society. To perform satisfactorily in this environment, managers and employees, inside of organizations, are compelled, daily, to make decisions and deliver results.

Gil, Arrima and Nakamura (2013) present a model of management which focuses on changes. They underscore two kinds of change, namely adaptation and innovation. The first is connected with globalized markets, and the second with knowledge expansion. In accordance with the authors, quality and intensity are the two determinants of change. They assert that managers need to monitor changes using information; this is a positive practice to keep business active and profitable.

Kaplan and Norton (2008) define management as a balancing system using metrics to evaluate various prospects of the organization. According to these authors, the execution premium consists of a management system to analyse strategies and operations. The process comprises planning, implementation and control within the new operational and strategic system of reports (operational dashboards and strategic scorecards). The system works from meetings in which learning processes are encouraged. During the meetings, reports are built, discussed and analyzed. In this environment, managers and employees are able to receive strategy and operational feedbacks, develop critical awareness and take decisions consciously.

For Müller (2014), the integration of strategic planning, indicators and processes is necessary and a determinant for entrepreneur success and sustainability. The continuation of an organization to act competitively depends on how managers analyze scenarios, how they select paths and strategies, and overall, how they structure their processes to follow these paths and to achieve their goals. According to Müller 'it is not enough to choose the route; you need to measure the processes' performance to know if the company is following in the planned direction' (p. 81, translation made by the author). Despite the purpose of a strategic plan being of vital importance, it needs to be linked with measurement tools for two reasons: because this is a way to rationalize resources, and because this is the best way to achieve goals.

Müller (Ibid, 2014), highlight that it is necessary to have a clear understanding of the strategy and the organizational structure to define a system of indicators. When managers create indicators overlook plans and competences, they run a strong risk of creating indicators that do not measure anything relevant and, therefore, will lead the company from nothing to nothing.

\section{Methodology Procedures}

The aim of this study is to propose a management instruments to monitor, evaluate and control organizational processes in the library and information unit. Management by indicators is the approach adopted because it contains all the requirements indicated by researchers and professionals of management and information science. The methodology 
procedures are presented in the following subsections.

\subsection{Epistemological and theoretical perspective}

This study requires an approach in which participative techniques should be applied. It was built based on the theoretical perspective of critical thinking within the subjectivist epistemological approach. Critical enquiry is adopted to establish the basis of this study because:

- It focuses on the participant's and researcher's critical awareness development as well as being concerned with problem solutions (Brookfield, 1987);

- It takes into account learning issues, and it is deals with knowledge exchange and sharing (Chambers, 2005).

- The research takes place inside discussion forums or other places where people can teach, learn and present their ideas simultaneously (Tavares, Hepworth \& Costa, 2011).

A subjectivist epistemological approach has been shown to be adequate in ascertaining that interaction between managers, employees and the researcher takes place. It is a learning process in which people can be involved in and committed to the problem solution. Discussion, negotiation and consensus are a way to develop critical awareness (Tavares, Hepworth \& Costa, 2011).

In addition, participatory research is the data-gathering methodology adopted. Kumar (2008) defined participatory research as an umbrella term from which different methods of participatory inquiry emerged, motivated by researchers' disenchantment with the positivist research paradigm, as well as from the critique of the researcher role in the developing world. According to the author, participatory research is deeply concerning with transformation, which, as a result, has the objective to create an environment of transformation, where the innovation can be raised.

Chambers (2005) asserts that participatory research is 'a family of approaches, behavior and methods for enabling people to do their own appraisal, to analyze their situation, to plan their actions, to take their own action, and to do their own monitoring and evaluation' (p.3). It is a way to build critical awareness and individual independency.

Management tools, when building collectively, become more appropriate to information units than any others since they are a way to implement changes in the involvement and commitment process. In fact, the main aim of participatory studies is to promote a learning environment inside the organization, such as a continuous process of discussion and negotiation to solve problems and take decisions.

In this study, all managers of first and second levels were invited to participate. In meetings, interviews or through the use of questionnaires, they discuss and get consensus about how to work, how to gather data, how to analyze these data and how to define what is important to be measured.

\subsection{Procedures to gather and analyze data}

Three underpinnings ideas were defined in order to guide participants in this study. These foundations were obtained from bibliographic reviewed, and are summarized below.

- Changes as a constant management process that gives origin to new plans and processes: plans should be constructed with the involvement of all within the constant learning process; the environment of discussion, negotiation and consensus has to be stimulated (Gil, Arrima \& Nakamura, 2013);

- A strategies and operations system needs to be implemented, and it is composed of planning, control and feedback processes: strategic meetings (focus on goals and objectives evaluation) and operational meetings (focus on actions and projects evaluation) have to be the primary method for taking decisions; (Kaplan \& Norton, 2008);

- Integration of strategic planning, organization processes and indicators must take place; a hierarchical measurement system has to be created that connects business, structure and execution, and all of this needs to be in close harmony with the plans and strategic goals (Müller, 2014).

In order to conduct the investigation, an intervention in an information unit ought to be done. In order to select a unit to be studied, the researcher took her consulting work during which an indicator system was built. The selected information unit is located in Brasília, the capital city of Brazil. It is an academic unit, where the management of scientific and technological information is its priority. The researcher worked in that information unit during seven months (from June, 2014 to January, 2015).

The first step of the investigation was to make an institutional diagnosis that served to raise the investigated unit features, notably their management practices. In this step, the researcher sought information by searching the information unit's database. Additionally, interviews with managers were conducted to collect perceptions and 
management practices. The data were analyzed and findings such as impropriated indicators and lack of the manager abilities to work with indicators were highlighted. These findings were used in the next step.

The second step was to survey measured references, which was considered the starting point to correct definition of indicators. In addition to findings from the first step, two sets of new data were gathered. First, by searching the information unit's database, and second, by applying questionnaires to the second and third management tier. The questionnaire contained in the first part, questions about the indicators in use by the investigated Unit. Figure 1 presents the structure of these issues.

\begin{tabular}{|c|}
\hline $\begin{array}{l}\text { 1. Indicator formula } \\
\text { 2. Description of formula's variables }\end{array}$ \\
\hline $\begin{array}{llll}\text { Is this indicator useful? } & (\text { ) Yes } & (\text { ) No } & \text { ( ) I don't know } \\
\text { Why? }\end{array}$ \\
\hline $\begin{array}{l}\text { Is this indicator easy to calculate? ( ) Yes } \quad(\text { ) No } \quad(\text { ) I don't know } \\
\text { Why___ }\end{array}$ \\
\hline $\begin{array}{l}\text { Is there another way to calculate this indicator? () Yes ( ) no ( ) don't know } \\
\text { If so, which is that? }\end{array}$ \\
\hline
\end{tabular}

Figure 1. Structure of the issues 1-18 of the questionnaire (by the authors).

Each issue asked the same question for each indicator specifically. The purpose is to assess the managers' understanding of each indicator. So, when they answer 'Yes' or 'No', justifying why they claim that they know about the indicator and can evaluate it critically. If, on the other hand, they answer 'don't know', they are claiming that they have no means by which they can assess, criticize or offer suggestions about any aspects of the indicator. By not responding, managers are positioning themselves as being uncompromising and uninvolved. In this case, depending on the incidence, the indicator must be rethought and/or managers need to be trained.

Two open questions were proposed at the end of the questionnaire. The first was to gather suggestions from other indicators. The second was to provide managers with the opportunity to present a single indicator that translates what the Information Unit does. The aim of this last question was to identify the most important process or strategy in the organization from the managers' point of view. Findings from this step comprise a large and detailed perception about indicator managed. Additionally, a set of measuring references was identified. Based on aspirations (what the organization wants to do) and regimental aspects (what the organization needs to do) the measuring references were established. These findings were equally used in the next step.

The third step of this investigation was to analyze both current indicators and measuring references to detect possible distortion and failures. The researcher worked closely with managers from the planning and institutional development area to exchange knowledge and experiences. This procedure led managers and the researcher to a strong understanding and mapping of the situation. Findings from this step comprise, mainly, the identification of indicators with problems. This finding represented the most important groundwork for the next step.

Finally, the last step was to analyze the data, which culminated in a set of indicators effectively linked to the reality of the investigated unit. Analyses were made of the data gathered, which at all stages took into account the grounded theory principles and coding in order to obtain an in-depth understanding of the investigated unit. As described above, this comprised several analyses, in a recursive way, during the process of the research. Data were collected repeatedly (interviews, questionnaires, database search), and confronted with new collections (interviews, questionnaires, database search) until a specific theory arose from this confrontation (Bryman, 2008). The raised theory was the measuring reference map and the indicators built from this map.

\section{Findings resulting from the application of the methodology}

The methodology was tested at an information unit located in Brasilia Federal District, Brazil. The objective of the researcher was to study and submit a proposal based on indicators specific to the information unit investigated. The results of this work are presented below.

\subsection{Measuring References}

A definition of measuring references, given by this study, is that they are active concepts based on abstract desire or 
regulation. In the case of the information unit investigated, both strategic planning and regimental assignments are abstract concepts. They are not well understood by everyone in the organization; it can be frequently seen that there are [some] managers and staff who do not know what exactly these abstract concepts mean.

Throughout the participatory techniques, these abstract concepts were disaggregated. Coding was the way to disaggregate the concepts, and with its use it was possible to convert abstract concepts (which almost none of the staff recognize) into a much more understandable concepts (which everybody recognizes). At the end of this process, the organization and its staff have a set of strategic and legal references (measuring references) that can be understood and, therefore, executed by all of them.

It is important to note that measuring references are directly related - the inverse of aggregation - with the abstract concepts of strategic planning and regimental assignments. This means that when people monitor and control measuring references, they are certainly achieving results that are expressed in the strategic planning and stabilized procedure. Figure 2 gives the graphic scheme of this methodology.

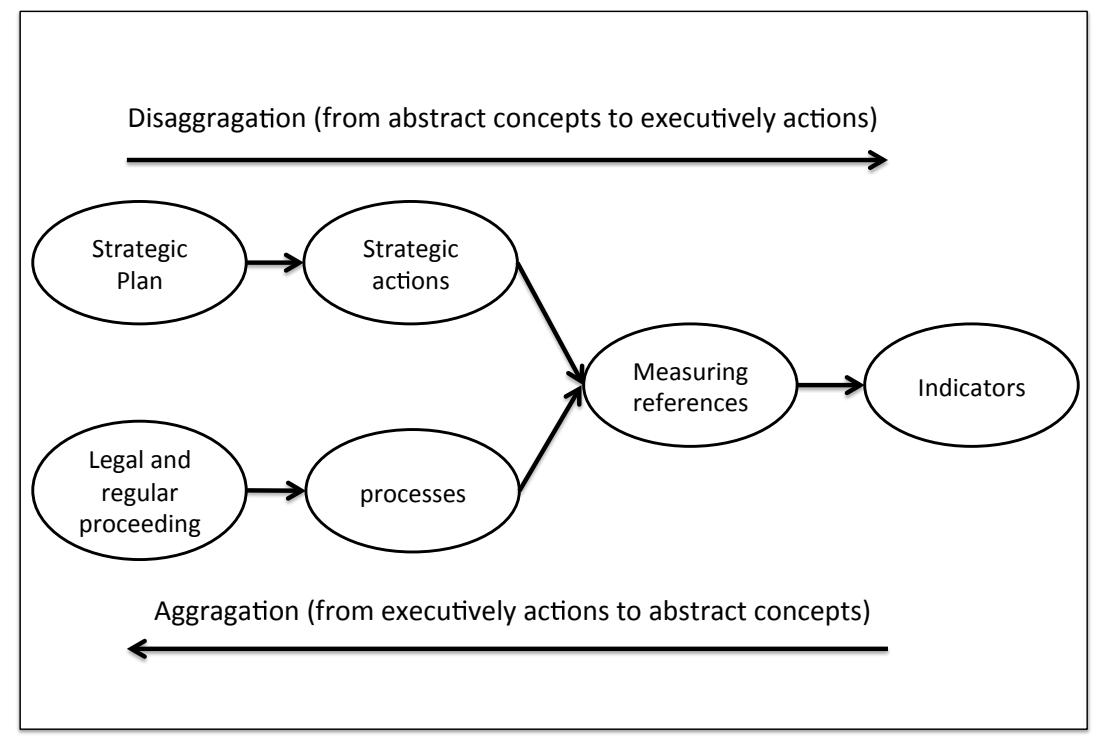

Figure 2. From planning and regimental assignments to measuring references (by the authors).

The key issues should be focused on how to identify correctly measuring references. In the case of the unit investigated, participants discussed concepts from strategic planning and codified these concepts repeatedly until getting measuring references. These references represent actions or statements that convert plans in goals, which could be achieved. Similarly, the same recursive coding procedures converted legal and regular proceeding in action or statements more managerial. The application of this process resulted in a list of measuring references described in Table 1 .

Table 1. Benchmarks measuring the synthesized information unit studied

\begin{tabular}{|c|c|c|}
\hline $\begin{array}{c}\text { Measuring references of } \\
\text { mission and vision }\end{array}$ & $\begin{array}{c}\text { Measuring references of strategic } \\
\text { actions }\end{array}$ & $\begin{array}{l}\text { Measuring references of } \\
\text { regimental assignments }\end{array}$ \\
\hline $\begin{array}{l}\text { Skills to produce and } \\
\text { manage information and } \\
\text { knowledge }\end{array}$ & $\begin{array}{l}\text { - Develop ICT skills } \\
\text { - Develop management skills }\end{array}$ & \\
\hline ICT infrastructure & $\begin{array}{l}\text { - Build a contemporary infrastructure } \\
\text { for transferring information for } \\
\text { market and industry, for integration } \\
\text { and sharing, and for research and } \\
\text { innovation }\end{array}$ & $\begin{array}{l}\text { - Upgrade of systems, network } \\
\text { and database }\end{array}$ \\
\hline $\begin{array}{l}\text { Production of information } \\
\text { and new knowledge }\end{array}$ & $\begin{array}{l}\text { - Develop research network groups } \\
\text { - Strengthen and expand national and } \\
\text { international partnerships }\end{array}$ & $\begin{array}{l}\text { - Upgrade of publishing } \\
\text { institutions and research } \\
\text { environment } \\
\text { - Enlarge international and }\end{array}$ \\
\hline
\end{tabular}




\begin{tabular}{|l|l|l|} 
& & national partnerships \\
\hline $\begin{array}{l}\text { Storage and preservation } \\
\text { of information and } \\
\text { knowledge }\end{array}$ & $\begin{array}{l}\text { - Develop structure for information } \\
\text { archive and for digital print } \\
\text { - Develop structure to achieve } \\
\text { Brazilian scientific and technological } \\
\text { production and to make it available to } \\
\text { international and national systems }\end{array}$ & $\begin{array}{l}\text { - Upgrade of information storage } \\
\text { structure } \\
\text { - Renovate library and research } \\
\text { systems }\end{array}$ \\
\hline $\begin{array}{l}\text { Dissemination and } \\
\text { availability of information } \\
\text { and knowledge }\end{array}$ & $\begin{array}{l}\text { - Develop structure for information } \\
\text { and knowledge dissemination } \\
\text { - Promote primary access of } \\
\text { documents, printed or electronic } \\
\text { papers }\end{array}$ & $\begin{array}{l}\text { - Upgrade of information and } \\
\text { knowledge dissemination system } \\
\text { needs }\end{array}$ \\
\hline
\end{tabular}

These are, in fact, the variables that need to be monitored, evaluated and controlled within the context of an information unit. Most situations should be contemplated in the specific plan, and, consequently, its measuring references. Because of this, participatory techniques are most appropriate for this kind of investigation, since they make it possible to build a specific management model that is complete and adequate for that organization.

\subsection{Indicators for the information unit}

The second step to define the management indicators was the creation of the indicators themselves. Conceptually, indicators were created based on one or more measuring references. The sequence can be represented by:

\section{Planning $\rightarrow$ Action $\rightarrow$ Measuring references $\rightarrow$ Indicators}

When created like this, indicators give the organization the guarantee of a strategic management that will lead to the institution reaching the desired results. It is important to remember that a pattern for creation and for measuring needs to be established. A pattern is useful because it establishes procedures as guidance. Thus, the staff will have a better understanding of the indicators, and the measuring will always be done in the same way. The standard must necessarily be compiled into a formal indicator document. The analysis of the measuring references resulting in the indicators is defined below.

\subsubsection{First reference: Develop skills and competencies}

For this benchmark, six indicators were proposed. They compare the number of trainings with budget, with attendance and approval, and with employee management, as presented below.

1. Training and employee management - index of training in technology of information and communication, comparing executed trainings with planned trainings

2. Training and employee management - index of annual budget for training, comparing what was spent on trainings with what was budgeted

3. Training and employee management - index of approval and applicability at work, comparing approval and applicability at work with executed trainings

4. Training and employee management - index of relative participation of fellow researchers, comparing number of fellow researchers with total of employees.

5. Training and employee management - Index of production of scholars, evaluate fellow researchers productivity

6. Training and employee management - index of relative participation of subcontractors, comparing number of subcontractors with total of employees.

It is important to note the structure of this set of indicators, in which all the strategies begin with the expression 'Training and employee management' thus including the whole group. Additionally, this measuring reference is so important for libraries and information units because it evaluates continuous training actions concerned with keeping a high level of innovation.

4.2.2 Second reference: infrastructure of Information and communication technology

For this benchmark, five indicators were proposed. They evaluate infrastructure investments, as presented below.

7. Infrastructure - index of technological modernization: comparing amount of new technological equipment acquired with existing technological equipment 
8. Infrastructure - index of automation of work processes: comparing amount of computerized work processes with existing amount of work processes

9. Infrastructure - index of investment in technological infrastructure: comparing amount of new technological equipment with existing technological equipment

10. Infrastructure - index of methodologies and technologies transferred: comparing the amount of methodologies and technologies transferred with the amount of methodologies and technologies developed or acquired

11. Infrastructure - index of methodologies developed or acquired: comparing the amount of methodologies and technologies developed or acquired with the existing amount of methodologies and technologies

As already mentioned at the beginning of the study, information units are faced with enormous challenges due to the great advances of information and communication technologies (ICT). Management of scientific and technological information, in this context, implies acting, all the time, in digital environments that require state-of-the-art technologies.

4.2.3 Third reference: Production of information and knowledge

For this benchmark, four indicators were proposed. They evaluate the information and knowledge production, as presented below.

12. Production - index general of the publications: comparing the amount of scientific production published with the number of researchers

13. Production - index of relative participation of national scientific production intelligence unit: comparing scientific production of organization with scientific national production

14. Production - index of the organization's participation in research projects developed: comparing the amount of participation in research projects with the number of researchers

15. Production - index of the participation in research that generates information products and services: comparing the amount of instrumental research that generates information products and services with the number of researchers

It is important to devise a system to monitor and control the production of qualitative and quantitative research. Also important is to motivate research that generates information products and services, because this is the best way to keep libraries and information units active and tangible.

\subsubsection{Fourth reference: Storage and preservation of information}

For this benchmark, two indicators were proposed. They evaluate the process of information and knowledge retrieved, as presented below.

16. Storage and preservation - index of database update: comparing the amount of scientific and technological production stored in the database in the last five years with the total amount of science and technology productions stored in the database

17. Storage and preservation - index of storage capacity: comparing the total number of science and technology productions stored in the database of the unit with the total number of scientific and technology productions stored in national level

In the information unit context, it is important to include indicators to measure the database timeliness, and also their storage capacity, because the main aim of units such is these is to store and retrieve scientific and technological information.

4.2.5 Fifth reference: Dissemination and availability of information

For this benchmark, two indicators were proposed. They evaluate the process of information and knowledge dissemination, as presented below.

18. Dissemination and availability - sum of items of information provided by information unit

19. Dissemination and availability - index of access to information by users, comparing the total number of accesses in the information database with the sum of information provided by information unit

Disseminated and available information is, conceptually, the last, but not least, measuring reference of libraries and information units. Within the processes of architecture, communication and mediation of information, researchers and professionals in information science are concerned with developing management techniques for preserving information 
and knowledge and making it available for researchers. If scientific and technological information is the main object of study of information science, its main product is available information.

\section{Conclusions}

This study presents a discussion about management in units of information, focusing on indicators for the monitoring, evaluation and controlling of administrative processes. Indicators proved to be efficient and effective because they contain all the evaluation requirements of the areas of management and information science, as indicated by the authors.

First, the proposed methodology defined indicators from a discussion and participation process (negotiation and consensus) that are prerequisites for the development of critical awareness and organizational learning. These skills help an organization in the process of change (innovation or adaptation), as asserted by Gil, Arrima and Nakamura (2013).

Additionally, the proposed methodology consisted of the planning process, feedback and control. There was a methodological process for the definition of indicators and measurement, in addition to the suggestion of strategic analysis meetings (focus on goals and objectives) and operational analysis meetings (focus on actions and projects). The management process was thus well defined and structured, as recommended by Kaplan and Norton (2008).

Finally, the basis for defining the measuring involved a large discussion about strategic planning, indicators and organizational processes that takes place with employees, managers and the researcher. In the proposed methodology, everything took place in close harmony with the plans and strategic objectives, as suggested by Müller (2014).

For this indicator system to be implemented, the definition of each indicator, by itself, is not enough. The effectiveness of this process depends on some subsequent actions, necessary for a complete and effective implementation:

- in order to not compromise the historic series, the basis for the indicator calculation must be formally defined; this formal definition ensures that the measurement will always be made in the same way, with the same periodicity and considering the same variables;

- for implementation it is necessary to establish the 'ground zero' for each indicator, from which goals will be fixed; this means that 'ground zero' is the first measurement, the starting point for any evaluation;

- the person who makes the measurement should not be the same person who works in the processes that are to be measured; this accumulation of functions is biased and compromises the value of the information given by the indicator;

It is important to note that a poor strategic plan definition can derail the indicator' definition. The study is based on the strategic plan, so if this was poor or out of context, the indicator would not measure relevant aspects. The flaw, however, is not in the method, but mainly the fact that there are interdependent relations between plans, regulations and measuring references.

Additionally, a large participation is required. In this investigation, only managers were invited to participate, due to research restrictions, but in future studies this should be enlarged to comprise all staff and, maybe, some users.

In this sense, two prerequisites are necessary for any work concerning indicators. First, to build a consistent, coherent and strategic plan set against the reality of the unit and its environment. This is the main condition for the success of work on the definition of indicators. The second is to obtain a participation that is as large as possible. This way plans can be efficient and effective.

\section{References}

Brookfield, S. (1987). Developing critical thinkers. San Francisco, USA: Jossey-Bass.

Bryman, A. (2012). Social research methods (4th ed.). New York, USA: Oxford University Press.

Chambers, R. (2005). Participatory workshops - a sourcebook of 21 sets of ideas and activities (4thed.). London: Earthscan.

Choo, C. W. (2006). A organização do conhecimento: como as organizações usam a informação para criar significado, construir conhecimento e tomar decisões. (Tradução Eliana Rocha.) (2a Edição). São Paulo, Brazil: Editora Senac.

Gil, A. de L., Arrima, C. H., \& Nakamura, W. T. (2013). Gestão: controle interno, risco e auditoria. São Paulo, Brazil: Saraiva.

Kaplan, R. S., \& Norton, Davi. P. (2008). A execução premium: a obtenção da vantage competitive através do vínculo da estratégica com as operações do negócio. (Trad.: Afonso Celso da Cunha Serra.) Rio de Janeiro, Brazil: Elsevier.

Kumar, S. (2008). Methods for community participation - a complete guide for practitioners (5th ed.). Warwickshire, England: Practical Action Publishing. 
Müller, C. J. (2014). Planejamento estratégico, indicadores e processos: uma integração necessária. São Paulo, Brazil: Atlas..

Tavares, R., Hepworth, M., \& Costa, S. (2011). The use of participatory techniques in the communication of information for communities: information literacy and collaborative work for citizen development. In: Developing people's information capabilities: fostering information literacy in educational workplace and community context. Bingley, England: Emerald Group Publishing Limited. http://dx.doi.org/10.1108/S1876-0562(2013)0000008019.

\section{(cc) $\mathrm{EY}$}

This work is licensed under a Creative Commons Attribution 3.0 License. 